\title{
Experimental Study of Impact Energy Absorption in Aluminium Square Tubes with Thermal Triggers
}

\author{
Nuno Peixinho*, Delfim Soares, Candida Vilarinho, Pedro Pereira, Dina Dimas \\ Departamento de Engenharia Mecânica, Escola de Engenharia, Universidade do Minho, \\ Campus de Azurém, CEP 4800-058, Guimarães, Portugal
}

Received: November 19, 2011; Revised: December 9, 2011

\begin{abstract}
This study presents an approach for the improvement of crashworthiness properties of aluminium tubular structures using initiators introduced through localized heating. The main objective of this approach is to improve the ability to absorb impact energy in a progressive and controlled manner by a local modification of material properties. Through a localized heating in areas previously chosen for initiation, associated with the softening of the aluminium alloy the deformation can be introduced precisely, forcing the tubular structure to deform in a mode of high energy absorption and reducing the maximum load in a controlled manner. This study presents the properties for an aluminium alloy 6061-T5 modified by thermal treatment by the use of a laser beam. Experimental results are presented of quasi-static and impact tests of tubular structures using the proposed approach. This concept appears as possible and effective in the experimental work presented.
\end{abstract}

Keywords: crashworthiness, quasi-static tests, dynamic tests, triggers, aluminium alloy 6061-T5, high speed camera

\section{Introduction}

This study presents experimental results obtained for a developed approach that consists in a local heating of aluminium alloy structures with the purpose of introducing a local change of material properties. The aim of this approach is the management of crash-energy absorption in a cost effective manner through the introduction of triggers that induce the tubular structure to initiate deformation in prescribed locations and assure deformation in the mode of highest energy absorption. The main objectives of the research work presented are the assessment of process feasibility using local heat-treatment for inducing a modification in material properties and the analysis if such local areas can effectively work as triggers for the folding process with advantages in crushing stability and load management.

Zhang and co-authors ${ }^{1}$ proposed a concept wherein by installing a buckling initiator near the impact end which is composed of a pre-hit column and pulling strips, the initial peak force of the square tube could be greatly reduced while the deformation mode and excellent energy absorption were retained. The investigation revealed that by using a buckling initiator, $30 \%$ reduction in the initial buckling force is achievable. It is also found that this buckling initiator can not only reduce the initial peak force, but also ensure a stable and uniform crushing mode ${ }^{1}$. Sunghak and co-authors ${ }^{2}$ evaluated the energy absorption performance of extruded aluminium alloys, using numerical simulation. Different types of triggering dents were introduced in the numerical simulation in order to evaluate the results of absorbed energy. J. Marsolek ${ }^{3}$ used non-axisymmetric folding patterns for an

*e-mail: peixinho@dem.uminho.pt improved control of absorption of kinetic crash energy. The trigger geometry mechanism was optimized for different loads, and the initial peak load was significantly reduced by using these types of triggers, especially in the dynamic experiments ${ }^{3}$.

The concept of using thermal modification of an aluminium alloy in localized areas can provide a larger global deformation of a part and higher energy absorption before failure. Therefore fracture in critical regions can be delayed and the total energy absorption can be accordingly increased. Such design features are also highly cost-effective in implementation compared to the alternative process of geometric redesign. This advantageous use of aluminium is therefore possible by applying "local material design", which in the present context is defined as controlled manipulation of material properties like strength, work hardening and ductility by means of non-homogenous heating ${ }^{4}$. In particular, the buckling of crash boxes during a crash situation may be controlled by deliberately imposing local soft zones (i.e. thermally induced triggers). For the impact event simulation tools can be used to assess crashworthiness performance ${ }^{5}$ and even enable a combined simulation of the thermal processing and subsequent response in the final component subjected to dynamic loading ${ }^{6}$.

\section{Material and Processing Parameters}

\subsection{Material}

The test specimens were manufactured from an aluminium alloy 6061-T5. The aluminium alloy was selected 
since it is commonly used in space frames for crash energy management. The T5 temper confers a higher strength to the alloy $^{7}$. The chemical composition of the alloy, determined by XRF spectrometry, is presented in Table 1 . The mechanical properties of the aluminium alloy 6061-T5, Figure 1, were obtained by static tensile tests with a Shimadzu AG-250 KNG hydraulic machine.

\subsection{Heating cycles}

The microstructure of the studied alloys can be modified as function of temperature and heating cycle applied. The most significant changes in the microstructure of the alloy occur for temperatures between 250 and $550{ }^{\circ} \mathrm{C}$ where a decrease in hardness arises, associated to the over ageing and dissolution effect of copper rich precipitates due to the imposed thermal cycle. The choice of the appropriated heating cycle parameters is of major importance for the purpose of alloy softening.

For carrying out the homogeneous heat treatment several samples were cut from an aluminium alloy sheet (average thickness $1.5 \mathrm{~mm}$ ). The cutted samples were then submitted to heat treatment: each sample has been placed in the central zone of a furnace for prescribed temperature and time.

Table 1. AA6061-T5 alloy chemical composition.

\begin{tabular}{ccccccc}
\hline & Al & $\mathbf{C u}$ & $\mathbf{F e}$ & $\mathbf{M g}$ & $\mathbf{M n}$ & $\mathbf{S i}$ \\
\hline Content (wt.(\%)) & Rest & 0.43 & 0.29 & 0.76 & 0.05 & 0.51 \\
\hline
\end{tabular}

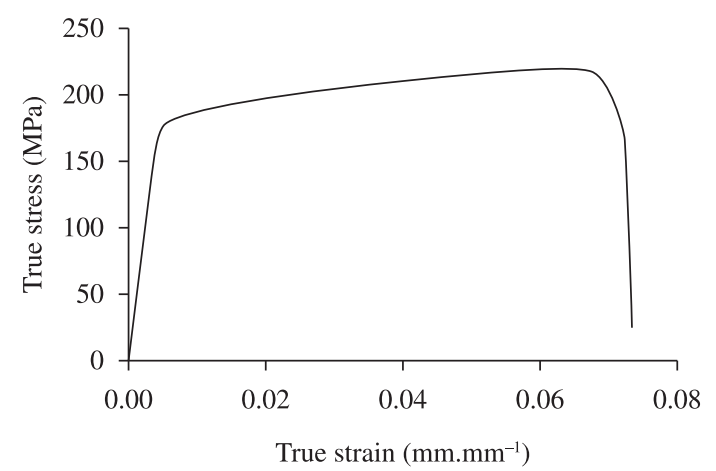

Figure 1. Aluminium alloy 6061 T5 true stress-strain curve of the initial (untreated) material.

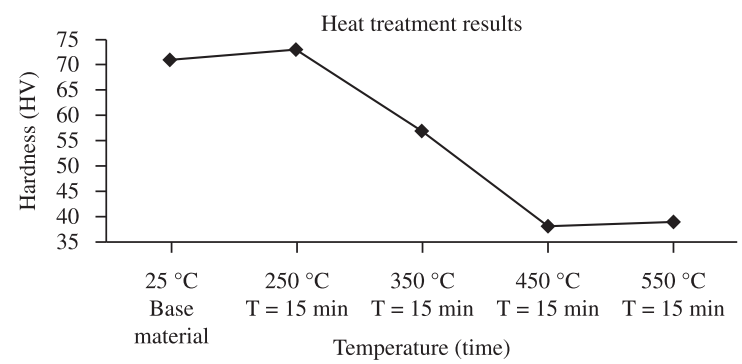

(a)
For the local heat treatment a $\mathrm{CO}_{2}$ laser welding machine was used (Trumpf $-4000 \mathrm{~W}$ ). This equipment was considered suitable for the local softening approach. The density of energy could be regulated from laser power and feed rate thus changing the heat affected zone.

Figure 2 shows the results of Vickers micro-hardness test with $100 \mathrm{gf}$ load, obtained on the top face of the tested sheet, for the samples with homogeneous heat-treatments, different tested temperatures and stage time. Temperature and time are presented for the furnace tests.

According to Figure 2 the hardness value is more dependent from the temperature heat treatment than stage time. In fact, hardness decreases in a significant way between 250 and $450{ }^{\circ} \mathrm{C}$, and presents little variation for different stages of time with a constant temperature.

The laser local heat treatment was used with a combination of different feed rates $(2,3$ and $5 \mathrm{~m} / \mathrm{min}$ ) and power input $(1,2$ and $4 \mathrm{~kW})$. The hardness results are presented in Figure 3. The different graphs present hardness values versus distance from laser path in order to evaluate the hardness in the HAZ (Heat Affected Zone). The results show similar values in the HAZ for power inputs of 1 and $2 \mathrm{~kW}$. At $4 \mathrm{~kW}$ and with a feed rate of $2 \mathrm{~m} / \mathrm{min}$ there is a significant increase of the HAZ.

\section{Experimental Testing}

\subsection{Quasi-static tests}

The structure considered in this study is a tubular column, of aluminium alloy 6061-T5, with a square crosssection. The dimension of the cross-section is $75 \times 75 \mathrm{~mm}$ with a wall thickness of 1,5 $\mathrm{mm}$ and a length of $300 \mathrm{~mm}$.

The experimental quasi-static tests were performed in a Shimadzu AG-250 KNG hydraulic machine that has a capacity of $250 \mathrm{kN}$ (Figure 4). The machine has been operated with a constant feed rate of $10 \mathrm{~mm} / \mathrm{min}$ and a maximum displacement of $150 \mathrm{~mm}$ (successive compression), being the quantitative information acquired by the machine software. The aluminium column has been positioned to prevent lateral movements or torsion.

\subsection{Dynamic tests}

Experimental impact tests were performed with a drop weight tower (Figure 5), presenting the following characteristics: drop mass of $76 \mathrm{~kg}$ and varying height up to $9.5 \mathrm{~m}$.

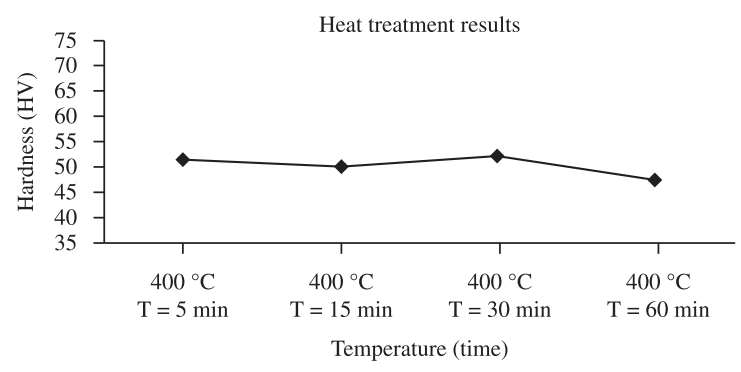

(b)

Figure 2. a) Hardness results for homogeneous (furnace) heat treatment at different temperatures. b) Effect of the stage time, at $400{ }^{\circ} \mathrm{C}$, in the hardness. 
Quantitative information was acquired with a high speed camera Photron Ultima APX-RS, at $5000 \mathrm{fps}$ and $512 \times 1024$ pixel resolution. The information acquired in the tests was processed by TEMA Motion software, with the digital images sequence obtained by the high speed camera, Figure 6. This software can tracks an object in the image and analyses its movement presenting results of displacement, velocity and acceleration, in the form of graphs and tables that can be exported to spreadsheet software for further treatment.

In TEMA Motion software the following parameters are defined: number of frames per second used in camera at the capture; the scaling, p/pixel; the point to track; and the tracking algorithms. The tracking algorithm is important to have a reliable tracking of the point by the software, in this case a correlation algorithm was used that scans in each successive image for the area that correlates best with the pattern defined in the first image.
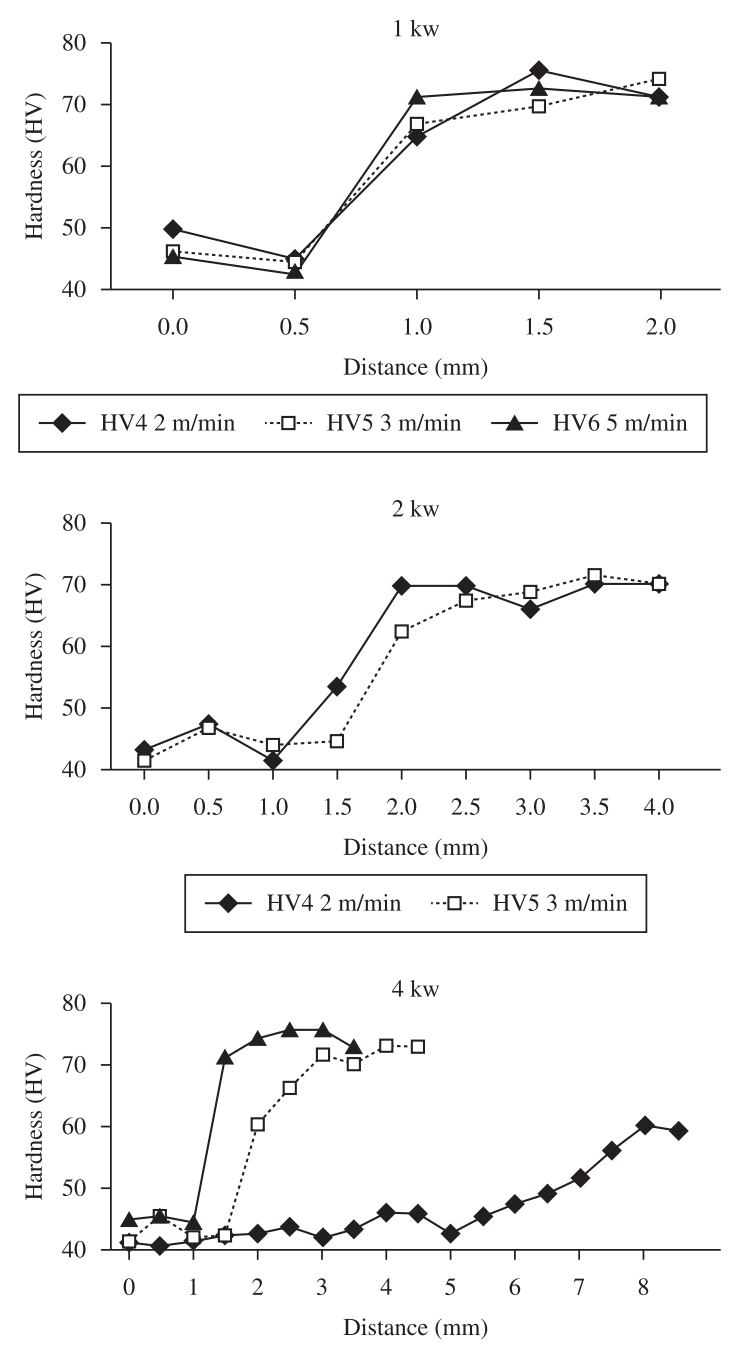

$\multimap \mathrm{HV} 12 \mathrm{~m} / \mathrm{min} \quad \cdots \square \mathrm{HV} 23 \mathrm{~m} / \mathrm{min} \longrightarrow \mathrm{HV} 35 \mathrm{~m} / \mathrm{min}$

Figure 3. Hardness results for laser heat treatment vs distance to the HAZ zone.
The software allows the use of FIR or CFC filters and in order to improve the obtained results the last one has been used. The CFC filter applies a fourth order phaseless Butterworth filter. This filter is a non-causal IIR (Infinite Impulse response) filter, i.e. a change in any input sample affects the entire output. Invalid input samples are interpolated and the corresponding output samples are marked as invalid. Input data is re-sampled to an equidistant timebase. The value used for this filter was CFC 500, according to the values used in crash analyses for sampling frequency of $5000 \mathrm{fps}^{[8]}$.

After obtaining the results of TEMA Motion analyses, those are exported to a spreadsheet (MS Excel) where the values of position, velocity and acceleration were analyzed in order to calculate mean load, maximum load, kinetic energy and total displacement.

\subsection{Results}

Load-displacement curves, values of maximum and mean crushing load, total energy absorbed and maximum

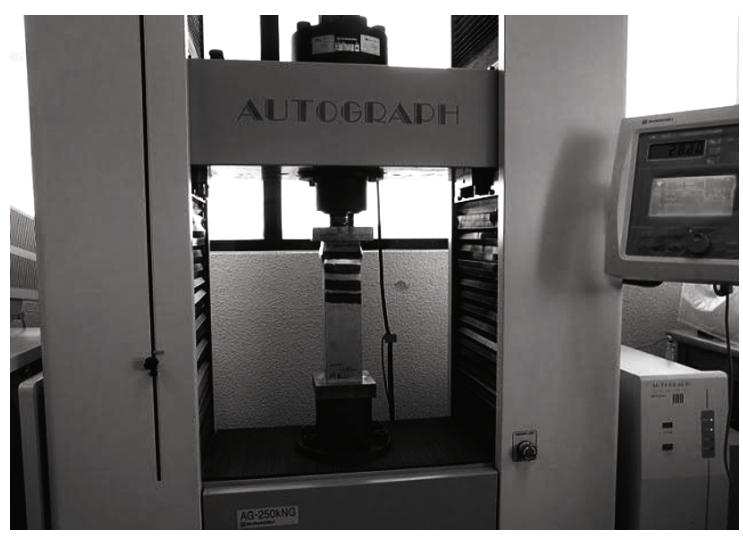

Figure 4. Shimadzu AG-250 KNG machine.

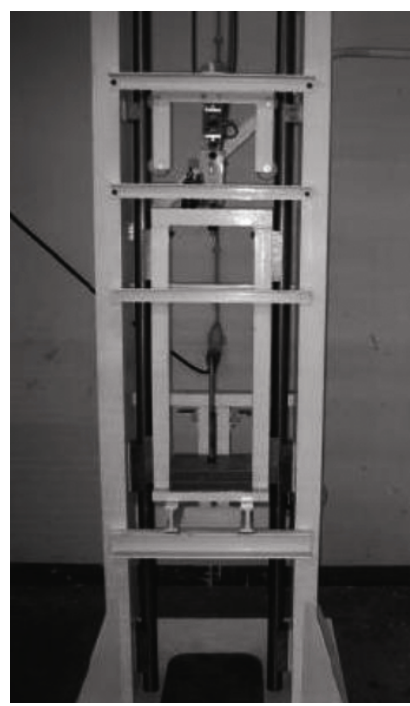

Figure 5. Drop weight tower tower. 


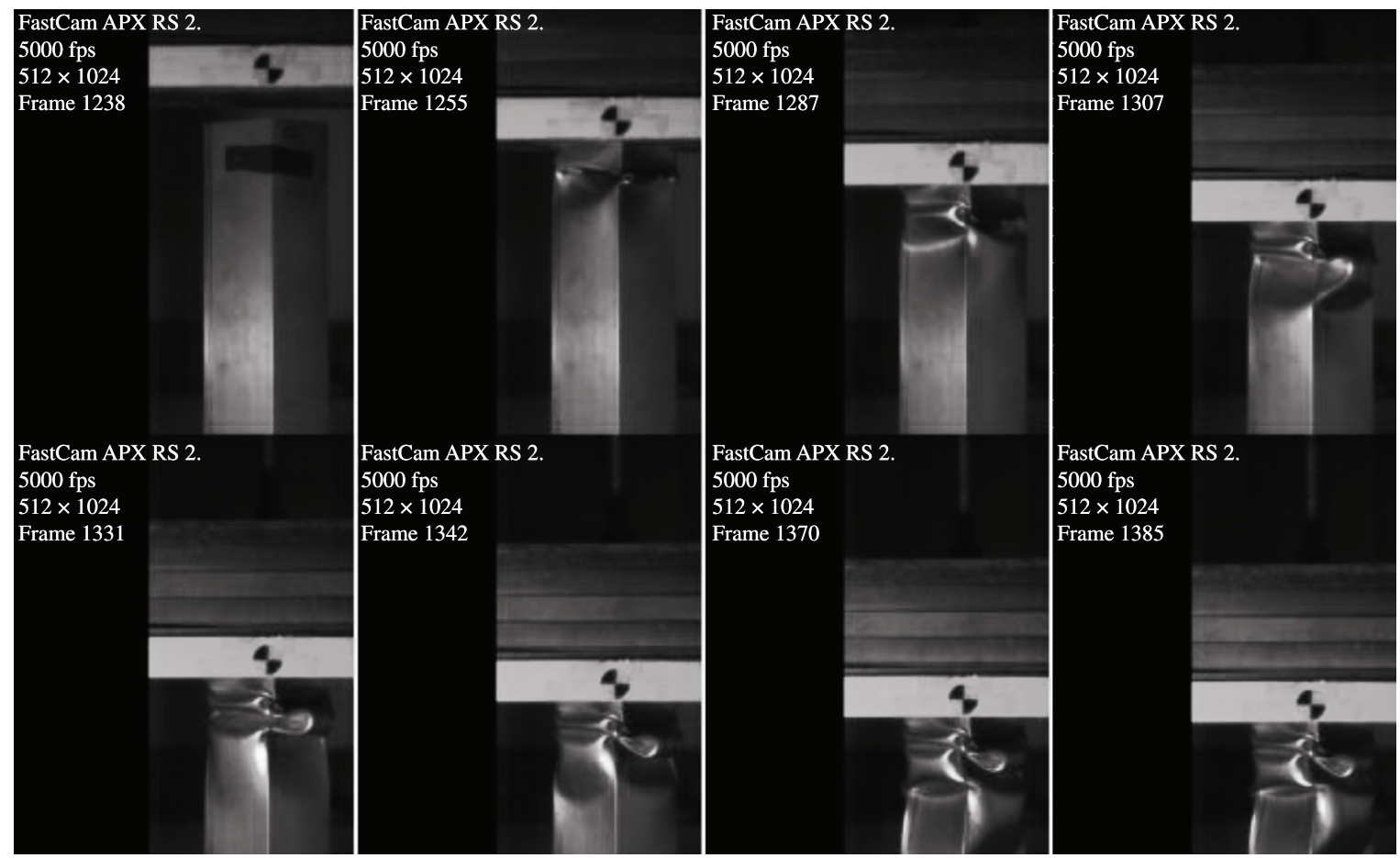

Figure 6. Example of sequential digital images

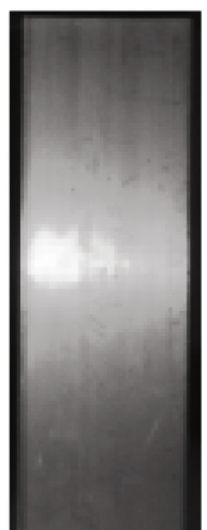

(a)

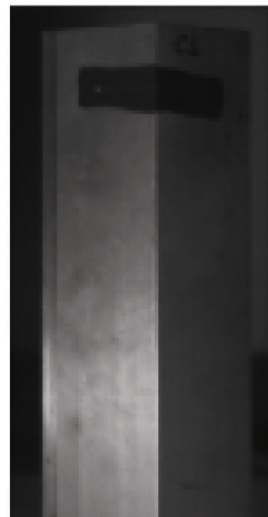

(b)

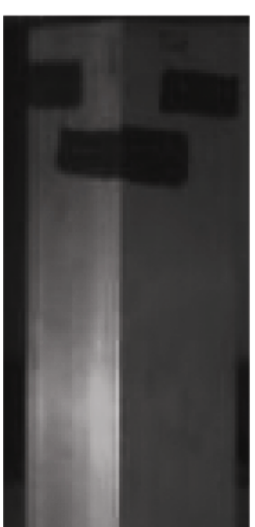

(c)

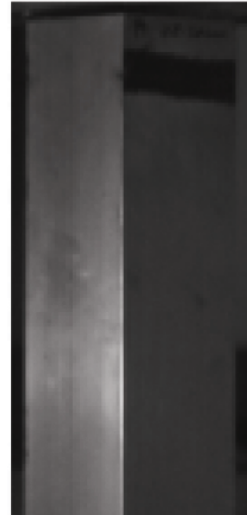

(d)

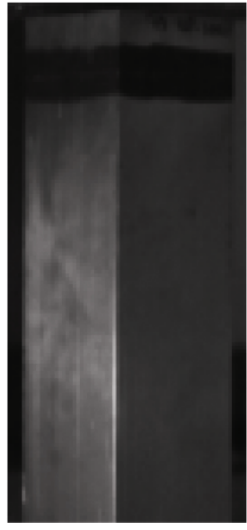

(e)

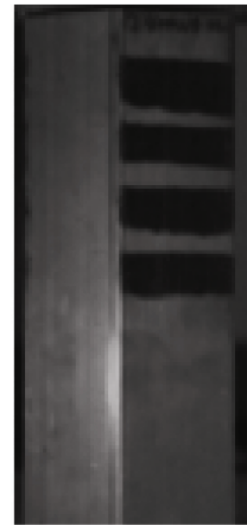

(f)

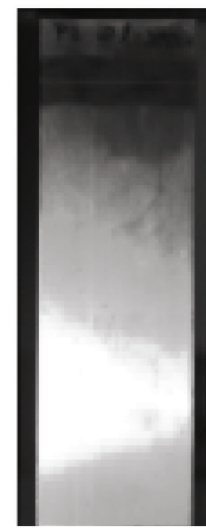

(g)

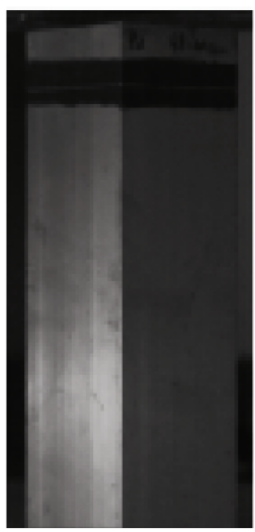

(h)

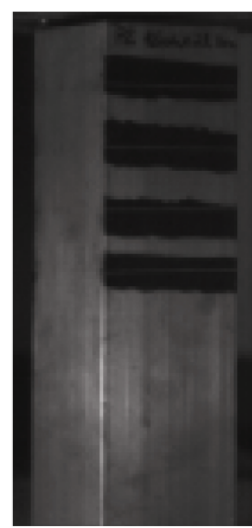

(i)

Figure 7. Type of trigger used as referenced in Table 2. 
displacement for each of the triggered tubular geometries and for one geometry without triggers have been evaluated during the experimental tests.

The type of the used triggers used is illustrated in Figure 7 and its characteristics shown in Table 2. Their geometry was chosen based on previous numerical simulation results ${ }^{9}$. The triggers described in Table 2 and illustrated in Figure 7 are arranged in the faces of the tubular structure at a distance of $30 \mathrm{~mm}$ from the top and spaced of $30 \mathrm{~mm}$ from each other if more than one trigger is used (for example, two triggers refers to two laser paths in a tube face). The choice of laser heat treatment parameters is also presented in Table 2 and is based on the results from Figure 3 seeking to evaluate the best parameters for local heat-treatment.

Table 2. Trigger characteristics.

\begin{tabular}{|c|c|c|c|c|c|c|c|c|c|c|}
\hline & & a) & b) & c) & d) & e) & f) & g) & h) & i) \\
\hline \multicolumn{2}{|c|}{ Sample Ref. } & w.t. & c1 & c2 & 2l-p1 & 4l-p1 & 4laser-p1 & 2l-p2 & 41-p2 & 4laser-p2 \\
\hline \multicolumn{2}{|c|}{ Trigger type } & $\begin{array}{l}\text { Without } \\
\text { trigger }\end{array}$ & $\begin{array}{l}\text { Complex } \\
\text { trigger } \\
\text { in two } \\
\text { faces }\end{array}$ & $\begin{array}{c}\text { Two } \\
\text { complex } \\
\text { triggers in } \\
\text { two faces }\end{array}$ & $\begin{array}{l}\text { One trigger } \\
\text { in two } \\
\text { opposite } \\
\text { faces }\end{array}$ & $\begin{array}{l}\text { One } \\
\text { trigger } \\
\text { in four } \\
\text { faces }\end{array}$ & $\begin{array}{l}\text { Four triggers } \\
\text { in two } \\
\text { opposite } \\
\text { faces }\end{array}$ & $\begin{array}{l}\text { One trigger } \\
\text { in two } \\
\text { opposite } \\
\text { faces }\end{array}$ & $\begin{array}{l}\text { One } \\
\text { trigger } \\
\text { in four } \\
\text { faces }\end{array}$ & $\begin{array}{c}\text { Four triggers } \\
\text { in two } \\
\text { opposite } \\
\text { faces }\end{array}$ \\
\hline \multirow{2}{*}{$\begin{array}{c}\text { HAZ } \\
\text { Parameters }\end{array}$} & $\mathrm{P}(\mathrm{kW})$ & - & 2 & 2 & 2 & 2 & 2 & 4 & 4 & 4 \\
\hline & $\begin{array}{c}\mathrm{V} \\
(\mathrm{m} / \mathrm{min})\end{array}$ & - & 2 & 2 & 2 & 2 & 2 & 3 & 3 & 3 \\
\hline
\end{tabular}

Table 3. Characteristic values for the quasi-static tests.

\begin{tabular}{|c|c|c|c|c|c|c|c|c|c|}
\hline & $\begin{array}{l}\text { w. t. } \\
\text { (a) }\end{array}$ & $\begin{array}{l}\text { c1 } \\
\text { (b) }\end{array}$ & $\begin{array}{l}\text { c2 } \\
\text { (c) }\end{array}$ & $\begin{array}{c}\text { 2l-p1 } \\
\text { (d) }\end{array}$ & $\begin{array}{c}\text { 41-p1 } \\
\text { (e) }\end{array}$ & $\begin{array}{c}\text { 4laser-p1 } \\
\text { (f) }\end{array}$ & $\begin{array}{c}\text { 2l-p2 } \\
\text { (g) }\end{array}$ & $\begin{array}{c}\text { 4l-p2 } \\
\text { (h) }\end{array}$ & $\begin{array}{c}\text { 4laser-p2 } \\
\text { (i) }\end{array}$ \\
\hline $\mathrm{P}_{\max }(\mathrm{kN})$ & 48.5 & 39.4 & 42.9 & 38.9 & 34.0 & 43.1 & 43.1 & 42.0 & 52.0 \\
\hline $\mathrm{E}_{\mathrm{a}}(\mathrm{kJ})$ & 2.4 & 2.3 & 2.8 & 2.3 & 2.3 & 2.6 & 2.3 & 2.3 & 2.8 \\
\hline $\mathrm{P}_{\mathrm{m}}(\mathrm{kN})$ & 15.9 & 15.3 & 18.4 & 15.4 & 15.1 & 17.2 & 15.2 & 15.2 & 19.0 \\
\hline$\delta_{\mathrm{f}}(\mathrm{mm})$ & 150 & 150 & 150 & 150 & 150 & 150 & 150 & 150 & 150 \\
\hline
\end{tabular}
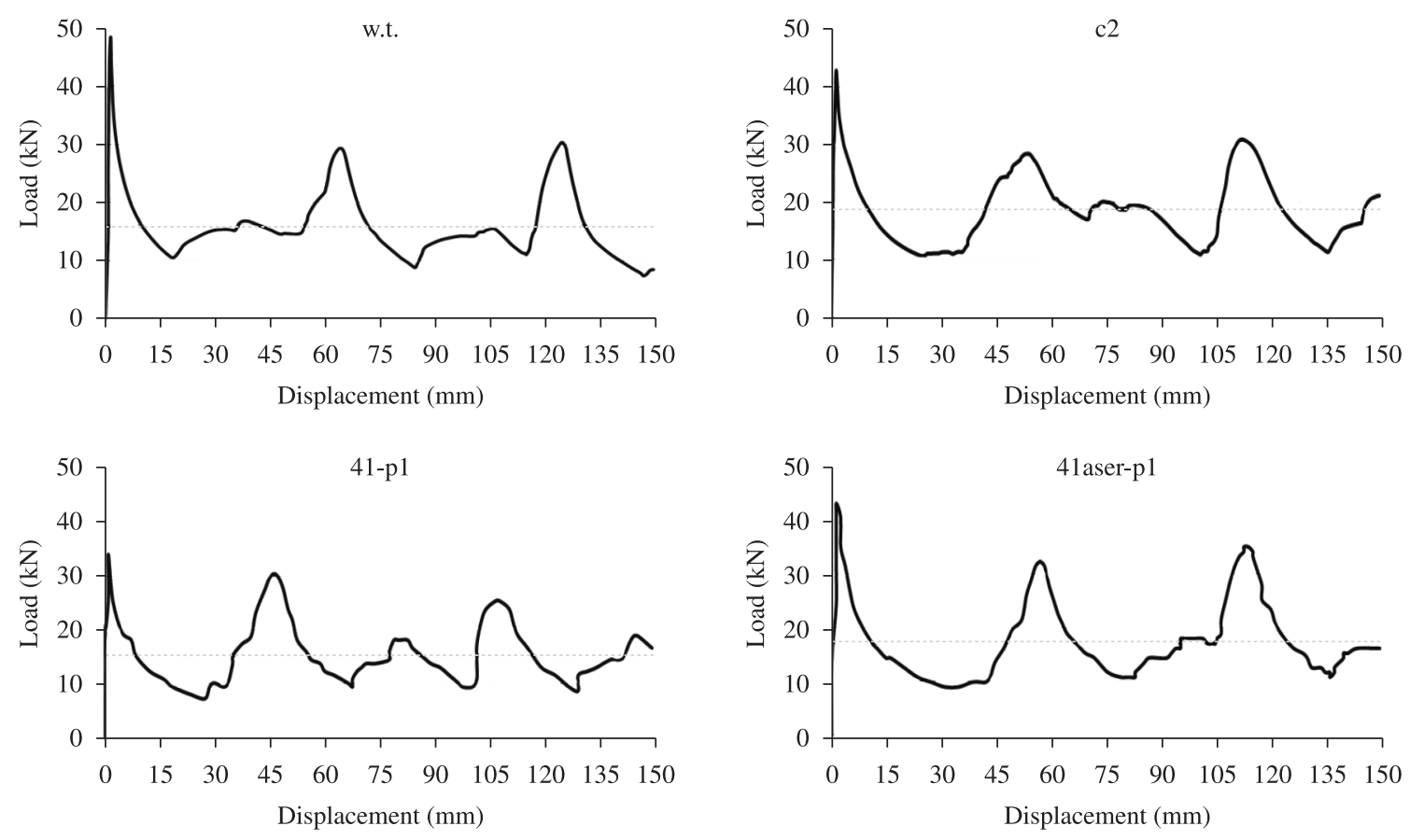

$\mathrm{Pm}$

Figure 8. Load-Displacement curves of the samples, w.t.; c2; 41-p1; 4laser-p1. 
Table 4. Characteristic values for the dynamic tests.

\begin{tabular}{|c|c|c|c|c|c|c|c|c|}
\hline \multicolumn{9}{|c|}{ Dynamic tests of tubes without triggers for different impact velocities } \\
\hline & & $\mathbf{v}(\mathbf{m} / \mathbf{s})$ & 9.102 & 10.115 & 10.049 & 9.378 & & \\
\hline & & $\mathbf{P}_{\max }(\mathbf{k N})$ & 76.3 & 52.7 & 36.8 & 29.3 & & \\
\hline & & $\mathbf{P}_{\mathrm{m}}(\mathbf{k N})$ & 20.5 & 21.0 & 21.1 & 17.2 & & \\
\hline & & $\delta_{\mathrm{f}}(\mathbf{m m})$ & 156.6 & 145.0 & 182.3 & 194.0 & & \\
\hline \multicolumn{9}{|c|}{ Dynamic tests of tubes with triggers for different impact velocities } \\
\hline & c1 & c2 & 21-p1 & 4l-p1 & 4laser-p1 & 21-p2 & 4l-p2 & 4laser-p2 \\
\hline $\mathbf{v}(\mathbf{m} / \mathbf{s})$ & 8.417 & 8.163 & 8.192 & 8.120 & 8.178 & 8.071 & 8.188 & 8.545 \\
\hline $\mathbf{P}_{\max }(\mathbf{k N})$ & 37.5 & 53.5 & 36.4 & 32.2 & 42.7 & 38.7 & 47.8 & 83.4 \\
\hline $\mathbf{P}_{\mathrm{m}}(\mathbf{k N})$ & 18.2 & 21.2 & 15.8 & 16.4 & 16.1 & 16.3 & 18.2 & 21.2 \\
\hline \multirow[t]{2}{*}{$\delta_{\mathrm{f}}(\mathbf{m m})$} & 148.4 & 120.2 & 161.8 & 153.1 & 156.9 & 152.1 & 140.3 & 133.6 \\
\hline & c1 & c2 & 2l-p1 & 4l-p1 & 4laser-p1 & 21-p2 & 41-p2 & 4laser-p2 \\
\hline $\mathbf{v}(\mathbf{m} / \mathbf{s})$ & 8.947 & 8.918 & 8.928 & 9.118 & 9.119 & 9.122 & 9.042 & 8.982 \\
\hline $\mathbf{P}_{\max }(\mathbf{k N})$ & 46.8 & 38.3 & 36.8 & 43.6 & 64.7 & 36.5 & 48.9 & 47.7 \\
\hline $\mathbf{P}_{\mathrm{m}}(\mathbf{k N})$ & 18.5 & 16.5 & 15.2 & 16.9 & 20.8 & 16.9 & 20.97 & 17.1 \\
\hline$\delta_{\mathrm{f}}(\mathbf{m m})$ & 164.2 & 183.9 & 198.9 & 187.5 & 153.4 & 188.4 & 148.2 & 179.7 \\
\hline
\end{tabular}

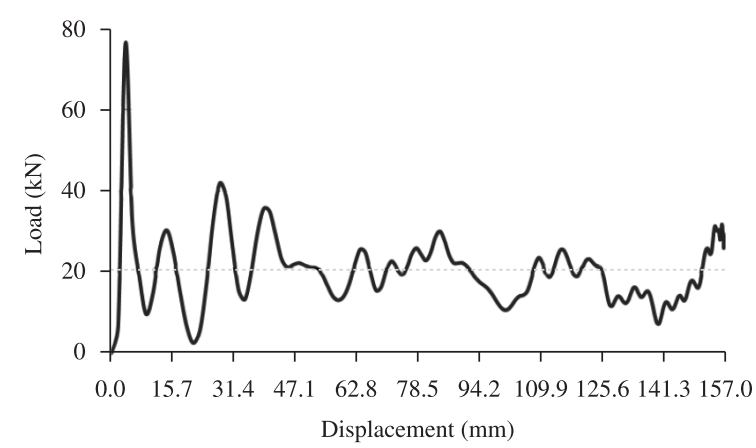

(a)

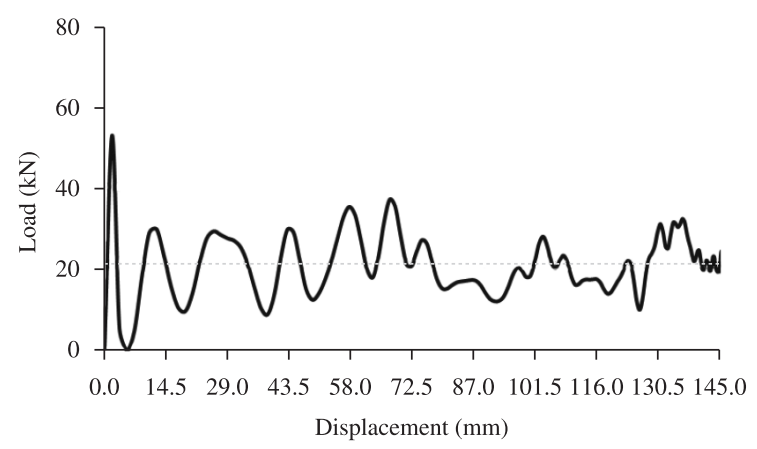

(b)

Pm

Figure 9. Load-Displacement curve of samples without triggers (w.t.), for dynamic tests at different impact velocities: a) $9.102 \mathrm{~m} / \mathrm{s}$; b) $10.115 \mathrm{~m} / \mathrm{s}$.

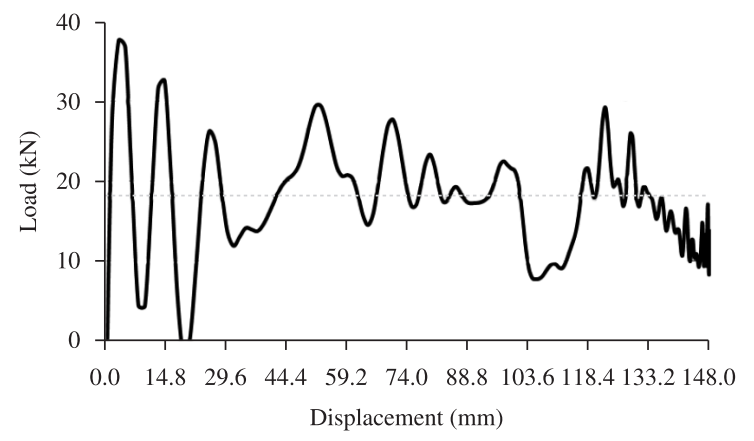

(a)

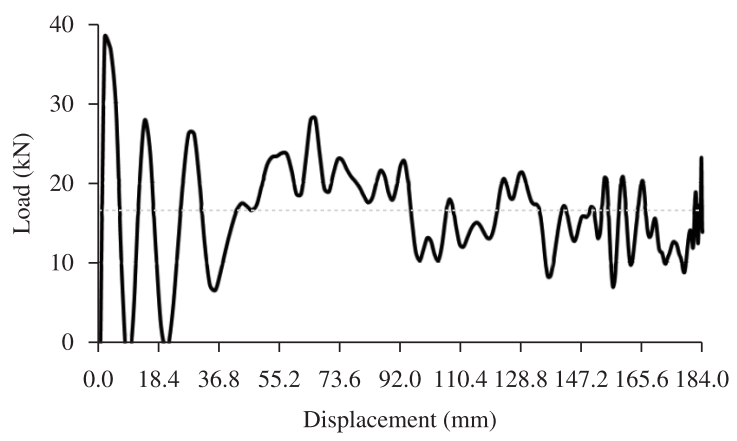

(b)

$\mathrm{Pm}$

Figure 10. Load-Displacement curve of samples: a) $\mathrm{c} 1$ and $\mathrm{v}=8.947 \mathrm{~m} / \mathrm{s}$; b) $\mathrm{c} 2$ and $\mathrm{v}=8.918 \mathrm{~m} / \mathrm{s}$. 


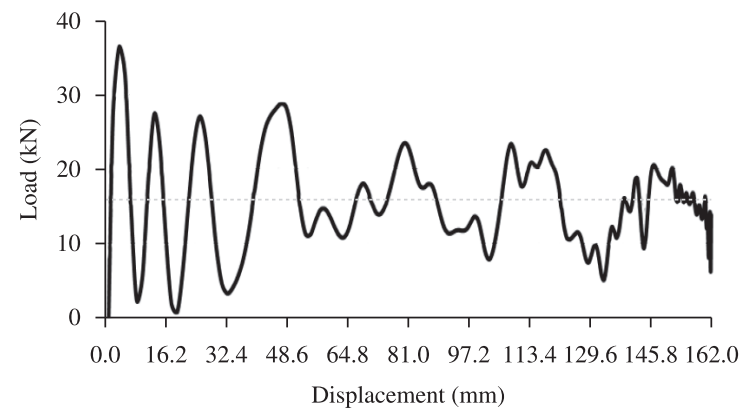

(a)

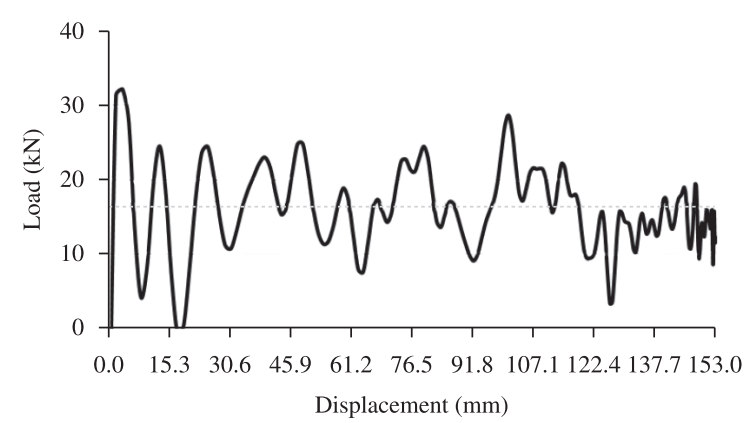

(b)

$\mathrm{Pm}$

Figure 11. Load-Displacement curve of samples: 21-p1and v $=8.192 \mathrm{~m} / \mathrm{s} ; \mathrm{b}) 41-\mathrm{p} 1$ and v $=8.120 \mathrm{~m} / \mathrm{s}$.

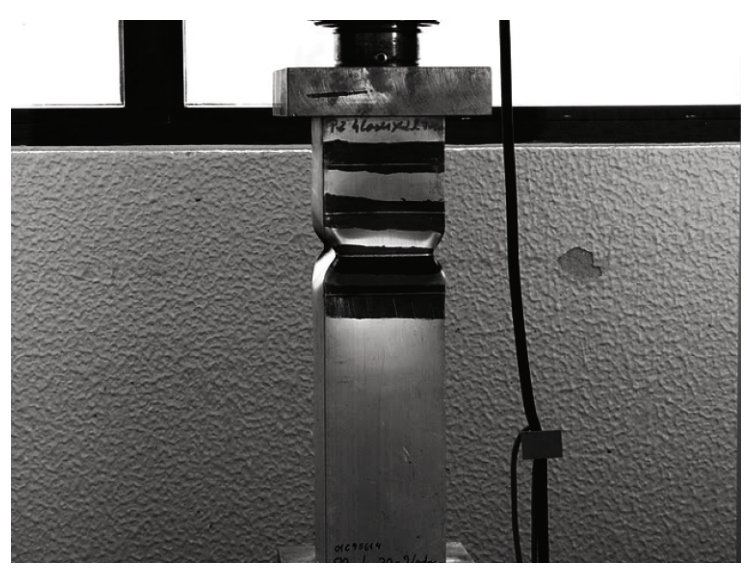

Figure 12. Initial plastic fold formed in geometry 4laser-p2.

Values of maximum load $\left(\mathrm{P}_{\max }\right)$, total absorbed energy $\left(\mathrm{E}_{\mathrm{a}}\right)$, medium load $\left(\mathrm{P}_{\mathrm{m}}\right)$ and final displacement $\left(\delta_{\mathrm{f}}\right)$ for each one of quasi-static tests are shown in Table 3 and the loaddisplacment curves of selected test results are presented in Figure 8. The recorded force-displacement curves were integrated with respect to the displacement to determine the mean crushing force. The mean load $\left(\mathrm{P}_{\mathrm{m}}\right)$ was calculated using the Equation 1:

$P_{m}=\frac{E_{a}}{\delta_{f}}$

Table 4 presents the exact values of maximum load $\left(\mathrm{P}_{\max }\right)$, total absorbed energy $\left(\mathrm{E}_{\mathrm{a}}\right)$, medium load $\left(\mathrm{P}_{\mathrm{m}}\right)$ and final displacement $\left(\delta_{\mathrm{f}}\right)$ for each one of the dynamic tests. Selected load-displacement curves are presented in Figures 9-11.

\section{Discussion}

When the first fold is forming, the model reaches the maximum force capacity, which represents the first peak and is referred to as the maximum peak force ${ }^{10}$. The load decreases as the first fold is being developed where the folding outward is started. After the completion of the first fold, the force reduces to the first lowest point where the contact outward happened. The further deformation causes the load to increase until the next peak is formed with the formation of the second fold. This sequence of peaks can be characterized by the mean crushing load, as presented by Equation 1. This load can be analytically predicted from simple calculations, and for regular geometries, as described in reference ${ }^{11}$. The maximum peak force is of more complicated analysis, both in experimental results and for design calculations. This load is a function of the impact velocity and is related to the speed of the elastic-plastic stress waves propagating along the tube. A reference for experimental and numerical analysis on dynamic buckling initiation for square tubes can be found in the work by Karagiozova and Jones ${ }^{12}$. Within the objective of obtaining controlled crushing behavior and lower peak forces triggers such as the ones studied in this paper can be applied. A first iteration for trigger location can be obtained through simple calculations of folding mode length, as described by Jones ${ }^{11}$.

For the quasi-static tests, it is possible to observe that the geometry $4 l-p l$ has the lowest peak force, followed by geometry $c 1$. These two geometries of HAZ triggers were made with the same parameters ( $p 1)$, being possible to observe that the geometries with parameters $p l$ have a lower maximum peak force than the geometries with parameters $p 2$. The total energy absorbed has similar values for almost every quasistatic tests. The geometry 4laser-p2 has a higher maximum peak of force in relative to the aluminum tube without HAZ trigger, this could be the influence of the plastic fold that starts in the third line of the HAZ trigger, as seen in Figure 12.

In the dynamic tests the observation of video recording and force-displacement curves allows the characterization of different features of the crushing process. Plastic folds are initially formed in the upper part of the test specimens and continue to develop gradually down into the lower parts, exception made for the geometries $c 2$, 4laser-pl and 4laser- 22 that have more than one HAZ line trigger and in rarely cases starts at the first line, Figure 13.

The complex geometry triggers, $c 1$ and $c 2$, present a different mechanism to absorb the impact energy. In these cases the aluminium tube starts to create a small vortex, unlike the other HAZ triggers geometries wherein as the folds initiate in a side of the model, they develop in the side opposed in turns. In the specific case of $c 2$ with an impact velocity of $8.163 \mathrm{~m} / \mathrm{s}$, a higher maximum peak of force is observed due to the initial plastic fold that initiate at the second line of the HAZ trigger. 
The impact velocity influences directly energy and the final displacement of axial crushing process. The dispersion of results in the tested geometries without triggers and the high $\mathrm{P}_{\max }$ observed in those tests indicate that square tubes have a low stability of the crushing process. In the opposite way the tubes with trigger mechanism have a more consistent

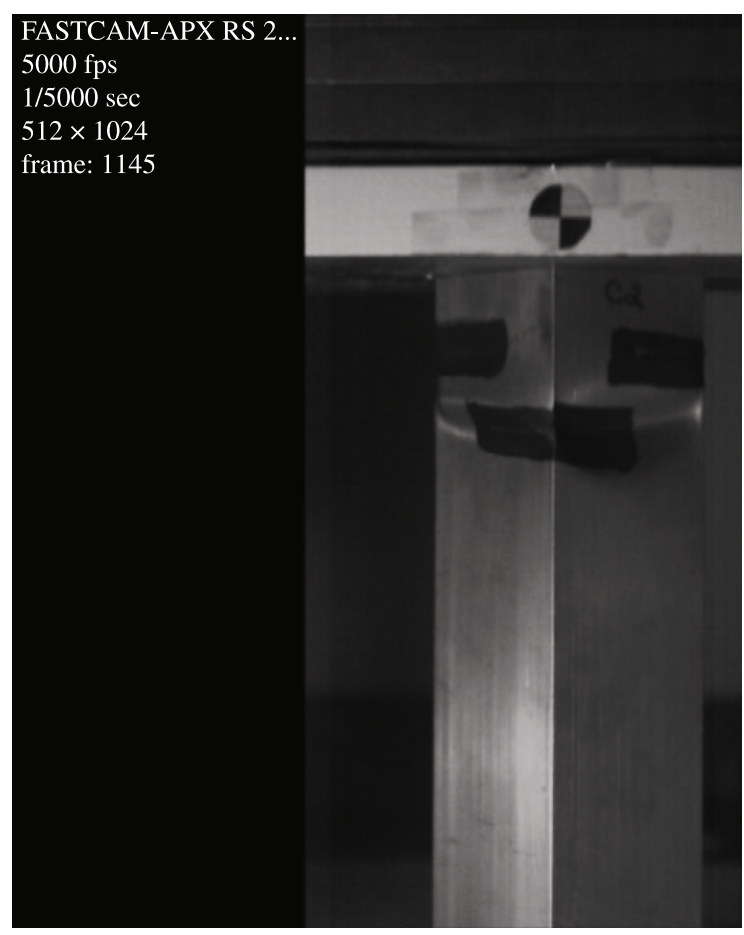

(a)

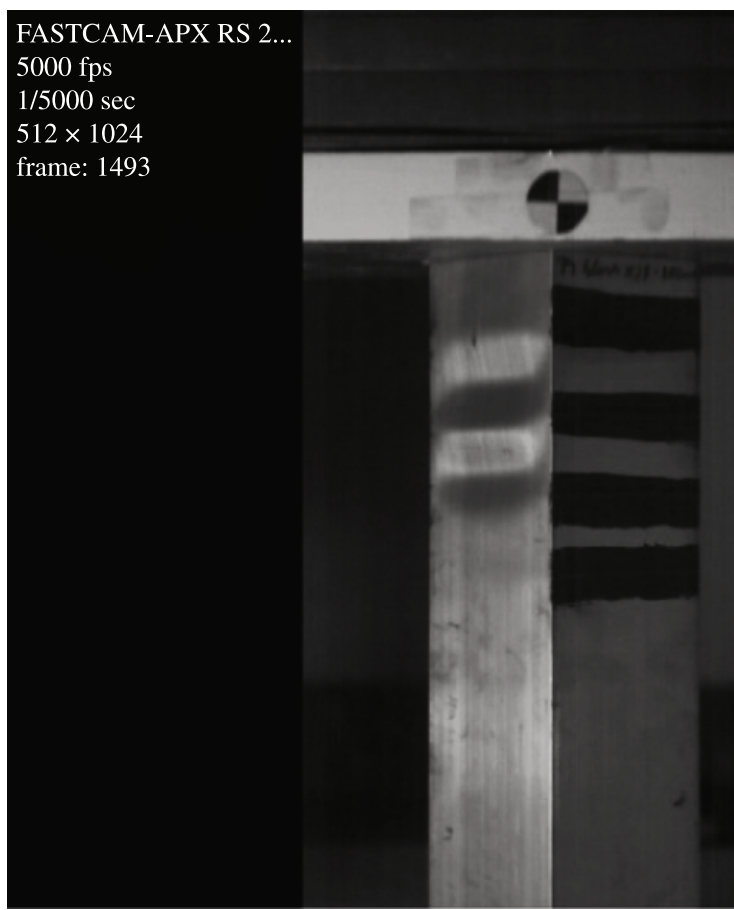

(c) way of deformation, and present an effective reduction of the maximum force, in particularly for the geometries $c 1$, $2 l-p 1,4 l-p 1$ and $2 l-p 2$. This reduction presents a benefit for crashworthiness purposes since it helps the reduction of the peak acceleration for occupants. However, this benefit must be weighed against a reduction in average mean crushing

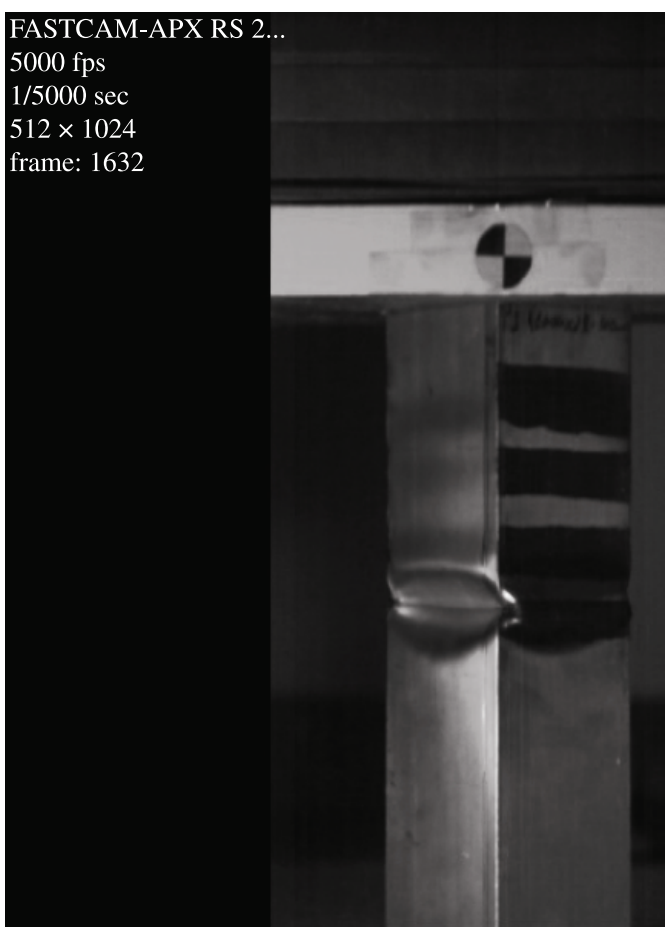

(b)

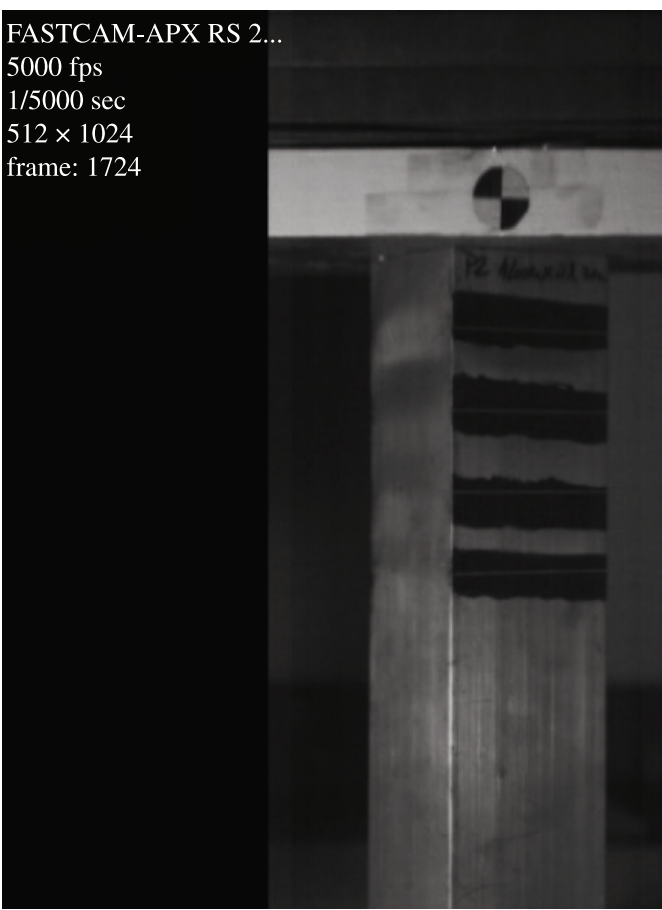

(d)

Figure 13. Initial deformation zones for different triggers geometries: a) c2; b) 4laser-p1; c) 4laser-p1; d) 4laser-p2. 


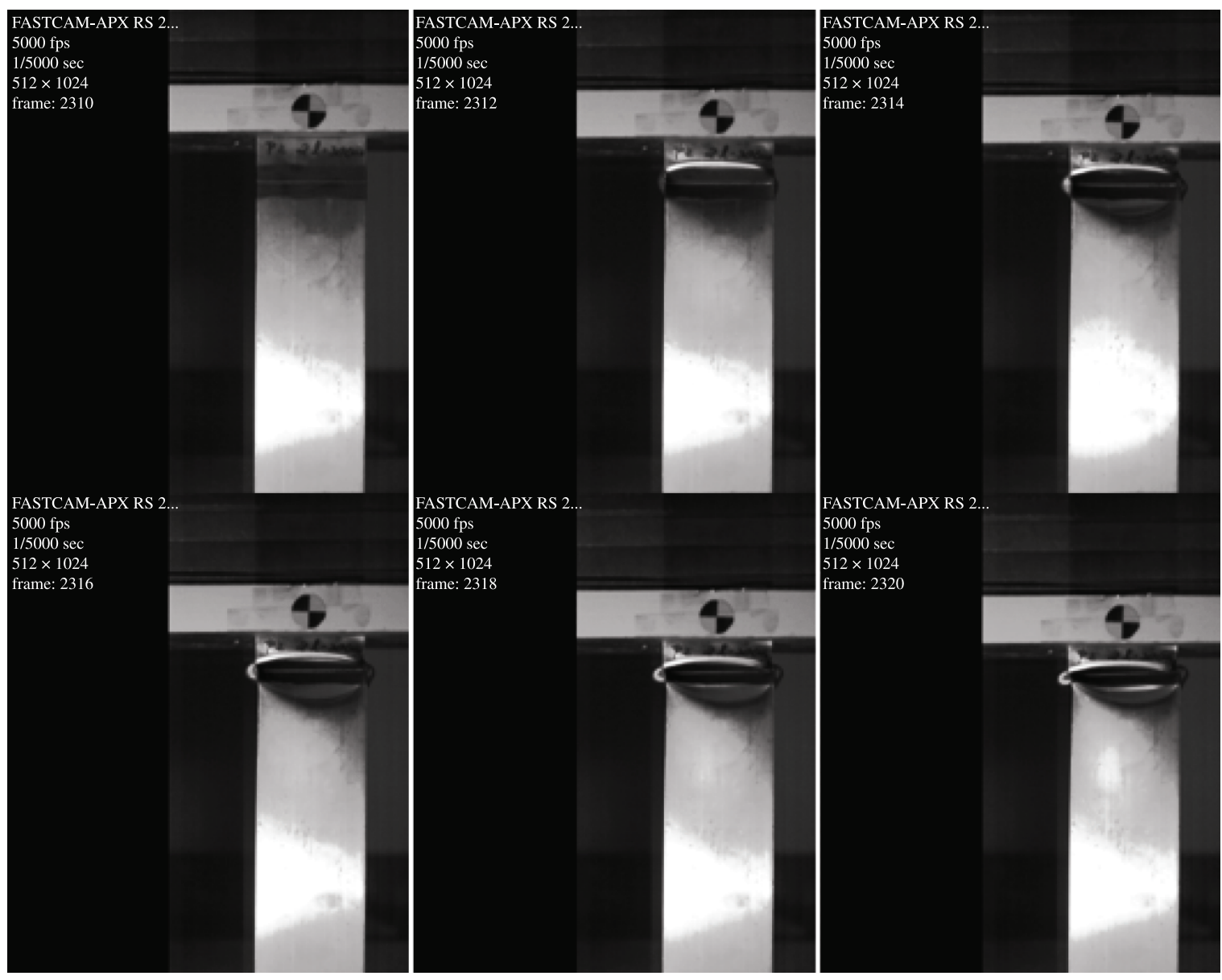

Figure 14. Folding process initiation at trigger location ( $2 l-p 2$ geometry).

force that also occurred for the referred tests. In particular, for the geometries $2 l-p 1,2 l-p 2$ and $4 l-p 2$ it is possible to see that independently of the impact velocity, the maximum force stays practically at the same values.

The objective of providing consistent triggering and therefore the ability to tailor the deformation process can be observed in Figure 14 where it can be seen that the folding process initiates at the thermal trigger location.

\section{Conclusions}

This paper presents experimental results of heattreatment of aluminum alloys with the purpose of inducing local modification of material properties. This was achieved using laser heat-treatment. Materials proprieties change with the heat treatment parameters (temperature and time of stage) and were evaluated in homogeneous preliminary tests. It was verified that it is possible to change the local hardness in a controlled way, that is, by the combined mechanisms of copper rich precipitates over ageing and dissolution effect in the sample. Local changes were achieved by the use of a laser treatment, specially, by changing the feed rate.

The quasi-static tests presented possibilities to reduce the maximum crushing force for almost all tested cases, exception made for the trigger geometry 4laser- $p 2$. For the tests performed in trigger geometries $p 2$ and 4laser-p1 an increase of mean crushing force is achieved. This reveals that it is possible to obtain HAZ parameters and triggers geometries that are according to the objectives.

The research reveals a dispersion of results for the dynamics tests. But in general it is observed that by using a thermal trigger a reduction in the initial crushing force is achievable. It is also found that this thermal trigger can not only reduce the initial maximum force but also ensure stable and uniform absorbed energy at most smart models, knowing that a usual problem for this specific kind of tubular structures is its stability, having a variability of deformation modes in impact loading.

The concept of using thermal modification of an aluminium alloy in localized areas for providing a larger global deformation of a part and higher energy absorption before failure appears as possible and effective in the experimental work presented.

\section{Acknowledgements}

The authors are grateful to the Portuguese Foundation for Science and Technology (FCT) who financially supported this work, through the project PTDC/EMEPME/65009/2006 


\section{References}

1. Zhang XW, Su H and Yu TX. Energy absorption of an axially crushed square tube with a buckling initiator. International Journal of Impact Engineering. 2009; 36(3):402-417. http:// dx.doi.org/10.1016/j.ijimpeng.2008.02.002

2. Lee $\mathrm{S}, \mathrm{Hahn} \mathrm{C}$, Rhee $\mathrm{M}$ and Oh J-E. Effect of triggering on the energy absorption capacity of axially compressed aluminhum tubes. Materials and Design. 1999; 20:31-40. http://dx.doi. org/10.1016/S0261-3069(98)00043-0

3. Marsolek J and Reimerdes H-G. Energy absorption of metallic cylindrical shells with induced non-axysimmetric folding patterns. International Journal of Impact Engineering. 2004; 30:1209-1223. http://dx.doi.org/10.1016/j. ijimpeng.2004.06.006

4. Bjørneklett BI and Myhr OR. Materials Design and Thermally Induced Triggers in Crash Management. In: Proceedings of the IBEC Conference; 2003; Madri. IBEC; 2003.

5. Peixinho $\mathrm{N}$ and Pinho A. Study of viscoplasticity models for the impact behaviour of high-strength steels. Journal of Computational and Nonlinear Dynamics. 2007; 2:114-123. http://dx.doi.org/10.1115/1.2447129

6. Fjær HG, Bjørneklett B and Myhr OR. Microstructure based modelling of Al-Mg-Si alloys in development of local heating processes for automotive structures. In: Proceedings of the 2005 TMS Annual Meeting; 2005. TMS; 2005.

7. Aluminium Association. Automotive Aluminium Crash Energy Management Manual. 1998.

8. Cichos D, De Vogel D, Otto M, Schaar O, Zolsch S, Clausnitzer S et al. Crash Analysis Criteria Description. version 2.1.1. 2008

9. Dimas D, Alves A, Peixinho N, Soares D and Vilarinho C. Configurable thermal-induced triggers for crashworthiness applications. In: Proceedings of Conference SMART'09-Smart Structures and Materials; 2009; Porto. Porto; 2009.

10. Marshall NS and Nurick GN. The effect of induced imperfections on the formation of the first lobe of symmetric progressive buckling of Thin-Walled Square Tubes. In: Jones N, Talaslidis DG, Brebbia CA and Manolis GD, editors. Structures under Shock and Impact. WIT Press; 1998.

11. Jones N. Structural Impact. Cambridge: University Press; 1997.

12. Karagiozova D and Jones N. Dynamic buckling of elastic-plastic square tubes under axial impact-II: structural response. International Journal of Impact Engineering. 2004; 30(2)167-192. http://dx.doi.org/10.1016/ S0734-743X(03)00062-9 